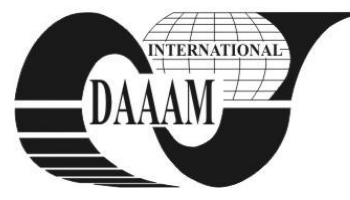

\title{
NON-LINEAR MATHEMATICAL MODEL OF A HEAT SOURCE WITH COMBINED PRODUCTION OF HEAT AND ELECTRIC ENERGY
}

\author{
NAVRATIL, P[avel] \& BALATE, J[aroslav]
}

\begin{abstract}
This paper describes the creation of non-linear mathematical model of combined heat and electric energy production plant for optimization of the operation of heat source. To creation of mathematical model were used historical data from combined heat and electric energy production plant Brno.

Key words: heat source, mathematic model, optimization, heat output, electric output
\end{abstract}

\section{INTRODUCTION}

The problem of economical distribution of load between cooperating production units arises at optimization of combined production of electric energy and heat production plants which have larger number of cooperating production units. Knowledge of power-economical characteristics of separate production appliances is the basic presumption of economical production, in our specific case it concerns consumption characteristics of boilers that generally have non-linear course. In this case its basic principle is to minimize fuel consumption for required heat output. From the mathematical point of view the aim of optimal control will be to achieve extreme value of objective function $E$, in this case minimization of production costs. In case the optimization of combined heat and power plant operation (Fig. 1.) can be carried out e.g. these methods, i.e. linear replacement of boilers consumption characteristics and non-linear replacement of boilers consumption characteristics.

Non-linear mathematical model of a heat source with combined production of heat and electric energy is described in this paper. Linear mathematical model is described e.g. in (Balate, 1969), (Phan, 1996), (Simek, 2007).

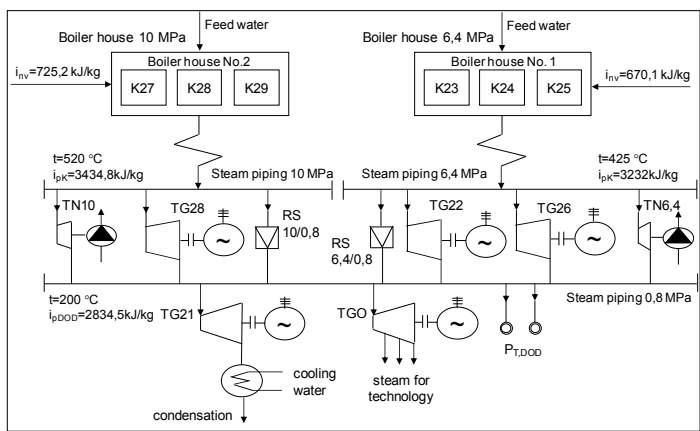

Fig. 1. Principle diagram of a combined heat and power plant

Legend: TN - Turbo-feed pump, TG - Back-pressure turbo-generator, TG21 Condensing turbo-generator, TGO - Bleeder steam turbine, RS - Reducing station, $\mathrm{P}_{\mathrm{T}, \mathrm{DOD}}$ - Heat output supply

The total immediate electric output $P$ will be calculated according to determined heat output supplied to the heat network $P_{T, D O D}$, where $P_{T, D O D}$ is the independent variable.

\section{NON-LINEAR MATHEMATICAL MODEL}

Consumption characteristics of boilers have generally nonlinear courses, characteristics of turbines have linear courses (see Fig. 2. - Fig. 4.). The course of consumption characteristic of boiler can be replaced by exponential approximation

$$
y=a . e^{\beta . x} \rightarrow P_{T, P A L}=a \cdot e^{\beta P_{T, K}}
$$

where $P_{T, P A L}$ - heat output in fuel, $P_{T, K}$ - heat output of boiler
The creation of non-linear mathematical model - theoretical part 1. Balance equation for steam piping $10 \mathrm{MPa}$

$$
\sum_{i=1}^{n, 10} a_{10, i} e^{\beta_{10, i} P_{T, K}^{10, i}}=\left[\left(\sum_{j=1}^{m}\left(\underline{P}_{T, T, V}^{10, j}+b_{T, V}^{10, j}\left(P^{10, j}-\underline{P}^{10, j}\right)\right)\right)+P_{T, N, V}^{10}+P_{T, R}^{10 / 0,8}\right] k_{q}^{10}(2)
$$

2. Balance equation for steam piping 6.4 MPa

$$
\sum_{i=1}^{n, 6.4} a_{6,4, i} e^{\beta_{6,4, i} P_{T, K}^{6 ., i}}=\left[\left(\sum_{j=1}^{m}\left(\underline{P}_{T, T, V}^{6.4, j}+b_{T, V}^{6.4, j}\left(P^{6.4, j}-\underline{P}^{6.4, j}\right)\right)\right)+P_{T, N, V}^{6.4}+P_{T, R}^{6.4 / 0.8}\right] k_{q}^{6.4}
$$

3. Balance equation for steam piping $0.8 \mathrm{MPa}$

$$
\begin{aligned}
& \sum_{j=1}^{m}\left(\underline{P}_{T, T, V Y}^{10, j}+b_{T, V Y}^{10, j}\left(P^{10, j}-\underline{P}^{10, j}\right)\right)+\sum_{j=1}^{m}\left(\underline{P}_{T, T, V Y}^{6.4, j}+b_{T, V Y}^{6.4, j}\left(P^{6.4, j}-\underline{P}^{6.4, j}\right)\right)+P_{T, N, V Y}^{10}+ \\
& +P_{T, N, V Y}^{6.4}+P_{T, R}^{10 / 0.8}+P_{T, R}^{6.40 .8}=\left[\sum_{j=1}^{m}\left(\underline{P}_{T, T, V}^{0.8, j}+b_{T, V}^{0.0 . j}\left(P^{0.8, j}-\underline{P}^{0.8, j}\right)\right)+P_{T, D O D}\right] k_{q}^{0.8}
\end{aligned}
$$

4. Total produced electric output

$$
P=\sum_{j=1}^{m, 10} P^{10, j}+\sum_{j=1}^{m, 6.4} P^{6.4, j}+\sum_{j=1}^{m, 0.8} P^{0.8, j}
$$

5. Objective function

Objective function expresses production costs for dependent variable $P_{T, K}$. It is necessary to calculate the values of this dependent variable for each value of independent variable $P_{T, D O D}$ - heat supplied to heat network (Fig. 1).

Then the objective function $E$ has this form

$$
E=\sum_{i=1}^{n, 10} a_{10, i}\left[e^{\beta_{10, i} P_{T, K}^{10, i}}-e^{\beta_{10, i} P_{T, K}^{10, i}}\right]+\sum_{i=1}^{n, 6,4} a_{6,4, i}\left[e^{\beta_{6,4, i} P_{T, K}^{6, i, i}}-e^{\beta_{6,4, i} P_{T, K}^{64, i}}\right]
$$

upon the conditions:

$$
\underline{P}_{T, K}^{r, i} \leq P_{T, K}^{r, i} \leq \bar{P}_{T, K}^{r, i} \quad\left(r=6.4,10 ; \quad i=1,2, \ldots, n_{r}\right)
$$

Non-linearity of the problem is in a difference of variables in (6), i.e. $\exp \left(\beta_{10, i} P_{T, K}^{10, i}\right)-\exp \left(\beta_{10, i} \underline{P}_{T, K}^{10, i}\right)$ and $\exp \left(\beta_{6,4, i} P_{T, K}^{6.4, i}\right)-\exp \left(\beta_{6.4, i} \underline{P}_{T, K}^{6.4, i}\right)$. Variables $\beta_{6.4, i}, \underline{P}_{T, K}^{6.4, i}, \beta_{10, i}, \underline{P}_{T, K}^{10, i}$ are considered as a constant.

Meaning of the variables in the equations:

$P_{T, K}[\mathrm{GJ} / \mathrm{h}]$ - the boilers output; $P_{T, T, V}^{10}, P_{T, T, V}^{6.4}[\mathrm{GJ} / \mathrm{h}]$ - the heat input on turbine inlet; $P_{T, T, V Y}^{10}, P_{T, T, V Y}^{6.4}[\mathrm{GJ} / \mathrm{h}]$ - the heat output on turbine outlet; $P_{T, N, V}^{10}, P_{T, N, V}^{6.4}[\mathrm{GJ} / \mathrm{h}]$ - the heat input on inlet of the turbo-feed pump; $P_{T, N, V Y}^{10}, P_{T, N, V Y}^{6.4}[\mathrm{GJ} / \mathrm{h}]$ - the heat output on outlet of the turbo-feed pump; $P_{T, R}^{10 / 0.8}, P_{T, R}^{6.4 / 0.8}[\mathrm{GJ} / \mathrm{h}]$ - the heat output of the reduction stations; $P_{T, D O D}[\mathrm{GJ} / \mathrm{h}]$ - the heat output supplied to the heat network; $k_{q}^{10}, k_{q}^{6.4}, k_{q}^{0.8}[-]$ - the coefficients of heat consumption or losses in each phase of technology; $b_{T, V}, b_{T, V Y}[\mathrm{GJ} / \mathrm{MWh}]$ - relative increment of heat consumption on turbine inlet, outlet; $P[\mathrm{MW}]$ - electric output

The symbol $\underline{X}$ or $\bar{X}$ in the (2) - (7) signs the minimum or maximum value of the appropriate quantity.

The creation of non-linear mathematical model - practical part Non-linear mathematical model was put together for the following conditions

- It is not necessary to consider reductions stations RS 10/0.8 and $6.4 / 0.8$, they have no practical assertion. 
- Several operational variants characterizing composition of cooperating production units were chosen. Out of these operational variants, which were utilized for application of the designed method, one operational variant is considered in further part. Operational variant represents composition of cooperating production units.

- Boilers No. K23-K24 have same efficiency curve.

- Consumption characteristic of the boiler K25 was elaborated from the known efficiency curve.

- Boilers No. K27-K29 have the same efficiency curve.

- Characteristics of back-pressure turbines have a linear course.

- Output of TGO (bleeder steam turbine) can be considered as constant $P=3.5 \mathrm{MW}$ (electric output) in winter season and $P=2 \mathrm{MW}$ in summer season. Further, it is considered arithmetical mean of these constants, i.e. $P=2.75 \mathrm{MW}$.

- In case that the consumed output of TG21 (terminal condensing turbine) will be $2-6 \mathrm{MW}$, it will concern utilization of independent electric output of the whole power and heating plant. Provided that the output of TG21 will be into $2 \mathrm{MW}$, it will concern utilization of dependent electric output of the whole power and heating plant.
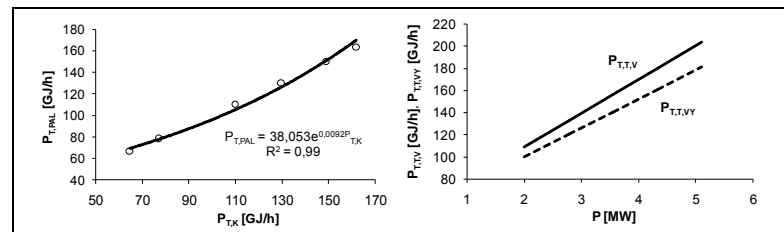

Fig. 2.Consumption characteristic of boilers K23, K24 and characteristics of back-pressure turbines TG22

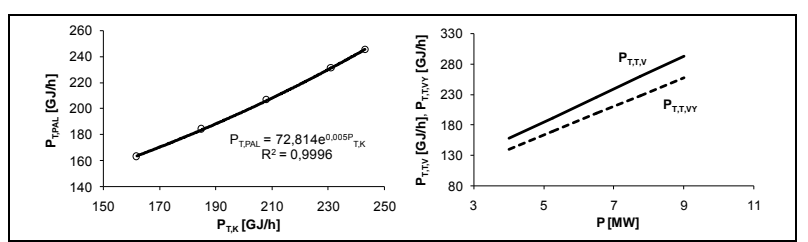

Fig. 3.Consumption characteristic of the boiler K25 and characteristics of back-pressure turbines TG26

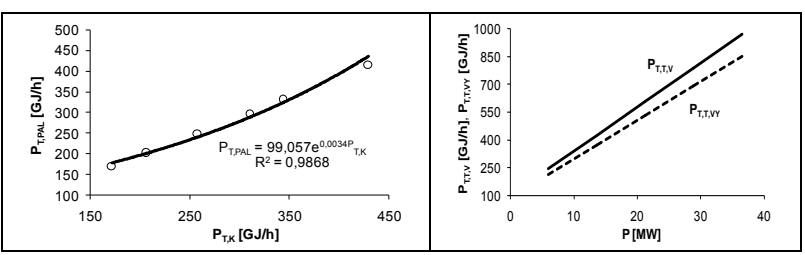

Fig. 4.Consumption characteristic of boilers K27, K28, K29 and characteristics of back-pressure turbines TG28

Balance equation for steam piping $10 \mathrm{MPa}$

$$
\begin{aligned}
& \sum_{i=1}^{3,10} a_{10, i} e^{\beta_{10,0} P_{T, K}^{10 . i}}=\left[\left(\sum_{j=1}^{1}\left(\underline{P}_{T, T, V}^{10, j}+b_{T, V}^{10, j}\left(P^{10, j}-\underline{P}^{10, j}\right)\right)\right)+P_{T, N, V}^{10}+P_{T, R}^{10 / 0.8}\right] k_{q}^{10} \\
& 99.057 e^{0.0034 f_{T, K}^{10.1}}+99.057 e^{0.00344 P_{T, K}^{10.2}}+99,057 e^{0.00344 P_{T, K}^{10.3}}= \\
& {\left[\left(243.02+23.84\left(P^{10,1}-6\right)\right)+50.91+0\right] 1.035}
\end{aligned}
$$

Balance equation for steam piping 6.4 MPa

$$
\begin{aligned}
& \sum_{i=1}^{3.64} a_{6,4, i} e^{\beta_{64,4, P_{T, K}^{6.3}}}=\left[\left(\sum_{j=1}^{2}\left(\underline{P}_{T, T, V}^{6,4, j}+b_{T, V}^{6.4, j}\left(P^{6.4, j}-\underline{P}^{6.4, j}\right)\right)\right)+P_{T, N, V}^{6.4}+P_{T, R}^{6.410 .8}\right] k_{q}^{6.4} \\
& 38.053 e^{0,0092 P_{T, K}^{6,4.1}}+38.053 e^{0,0092 P_{T, K}^{6.42}}+72.814 e^{0,005 P_{T, K}^{6,4.3}}= \\
& {\left[\left(108.94+30.38\left(P^{6,4,1}-2\right)\right)+\left(157.13+27.15\left(P^{6,4,2}-4\right)\right)+48.6+0\right] 1.015}
\end{aligned}
$$

Balance equation for steam piping $0.8 \mathrm{MPa}$

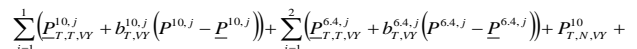

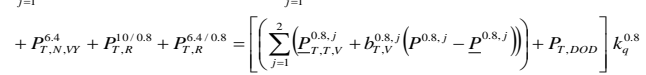

$$
\begin{aligned}
& 213.69+20.95\left(P^{10.1}-6\right)+\left(99.72+26.23\left(P^{6.4 .1}-2\right)+139.53+23.46\left(P^{6.4 .2}-4\right)\right)+43.91 \\
& +39.72+0+0=\left[\left(57.82+69.14(2.75-0.8)+53.63+31.43\left(P^{0.8 .2}-2\right)\right)+P_{T, D o D}\right] 1.066
\end{aligned}
$$

Total produced electric output

$$
P=\sum_{j=1}^{1.10} P^{10, j}+\sum_{j=1}^{2.644} P^{6,4, j}+P_{T G O}^{0.8,1}+P_{T G 21}^{0.8,2}=P^{10,1}+P^{6,4,1}+P^{6,4,2}+2.75+P_{T G 21}^{0.8,2}
$$

Objective function

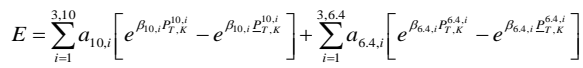

$$
\begin{aligned}
& =99.057\left[e^{0.0034 t_{I}^{\prime}, 0.1}-e^{0.003420615}\right]+99.057\left[e^{0.0034 P_{I, K}^{10.2}}-e^{0.0034171 .79}\right]+ \\
& +99.057\left[e^{0.0034 t_{t, K}^{10.3}}-e^{0.0034171 .79}\right]+38.053\left[e^{0.0092 P_{t, K}^{6.1}}-e^{0.009264 .95}\right]+
\end{aligned}
$$

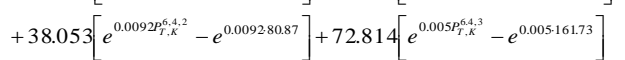

Limiting non-negative conditions:

$$
\begin{array}{llll}
206.57 \leq P_{T, K}^{10,1} \leq 398.05 & {[\mathrm{GJ} / \mathrm{h}]} & 171.79 \leq P_{T, K}^{10,2} \leq 343.58 & {[\mathrm{GJ} / \mathrm{h}]} \\
171.79 \leq P_{T, K}^{10.3} \leq 343.58 & {[\mathrm{GJ} / \mathrm{h}]} & 64.95 \leq P_{T, K}^{6.4,1} \leq 145.81 & {[\mathrm{GJ} / \mathrm{h}]} \\
80.87 \leq P_{T, K}^{6.42} \leq 161.73 & {[\mathrm{GJ} / \mathrm{h}]} & 161.73 \leq P_{T, K}^{66.3} \leq 243.02 & {[\mathrm{GJ} / \mathrm{h}]} \\
6 \leq P^{10,1} \leq 36.5 & {[\mathrm{MW}]} & 2 \leq P^{6.4,1} \leq 5.1 & {[\mathrm{MW}]} \\
4 \leq P^{6.4,2} \leq 9 & {[\mathrm{MW}]} & 2 \leq P_{T G 21}^{0.8,2}=P^{0.8,2} \leq 6 & {[\mathrm{MW}]}
\end{array}
$$

The change of independent electric output of terminal condensing turbine TG21 is consider in range 2-6 MW. Heat output supply value $P_{T, D O D}$ is considered in range $300-900 \mathrm{GJ} / \mathrm{h}$.

It was suggested procedure for optimization of the operation of heat source for determined mathematical model. This procedure, i.e. solution of non-linear optimizing problem via solution of a certain linear optimizing problem (i.e. without execution of linearization of consumption characteristics of boilers), is used for determining of load distribution of separate production units (boilers) and for determining of electric output (dependent and independent electric output) produced by separate separate turbines. To solution of described problem the simplex method (Dantzig, 1963) was used. At looking for solution for determined mathematical model, there were used possibilities of the program MATLAB, especially "Optimization toolbox".

\section{CONCLUSION}

This paper has described creation of non-linear mathematical model of combined heat and electric energy production plant. To creation the mathematical model was used historical data from heating plant Brno. Obtained results from solution of mathematical model could be used as a base for operative planning and also for own operation control of production of heat and electric energy in real time. Mentioned results could also be used as input values for control of heat supply to consumer, i.e. for heat distribution. One of possible approach to control is e.g. the so called qualitative-quantitative way of control of hot-water piping heat output for heat supply to district heating system (Balate et al., 2006).

\section{ACKNOWLEDGEMENT}

This work was supported in part by the Ministry of Education of the Czech Republic under grant No. MSM 7088352102 and in part by the project of National Research Programme II No. 2 C06007.

\section{REFERENCES}

Balate, J. (1969). Design of optimal control of heat output of district heating systems sources in Brno locality. Dissertation work, Brno (in Czech)

Balátě, J., Jeník, P., Chramcov, B., Navrátil, P. (2006). The Way of District Heating Output Control by Means of Hydrothermal Power Systems - Three Modifications. CDROM Proceedings of the IFAC Symposium on Powers Plants and Power Systems Control, Kananaskis, Alberta, Canada, Paper No. 583, DOI: 10.3182/20060625-4-CA-2906.00072

Dantzig, G. B. (1963) Linear Programming and Extensions. Princeton, Princeton University Press, NJ

Phan, T.D. (1996). Algorithms of optimal control in production and heat distribution. Diploma work, Zlin (in Czech)

Simek, J. (2007). Optimal control of the heat source with combined production of heat and power. Diploma work, Zlin (in Czech)

*** (2009) Optimization Toolbox, MATLAB 